\title{
The Association between Various Lifestyle Patterns and the Body Mass Index in Adolescents
}

\author{
Irina-Bianca Kosovski ${ }^{1}$, Dana-Valentina Ghiga ${ }^{\star}$, Monica Tarcea ${ }^{3}$, Cristina Nicoleta Ciurea ${ }^{4}$, Ana loana \\ Savin ${ }^{5}$, Anca Bacârea ${ }^{6}$ \\ 1. Clinical laboratory Department of Emergency Clinical County Hospital of Târgu Mures, Romania \\ 2. Research Methodology Department, University of Medicine, Pharmacy, Science and Technology of Târgu Mures, Romania \\ 3. Community Nutrition and Food Safety Department, University of Medicine, Pharmacy, Science and Technology of Târgu Mures, Romania \\ 4. Microbiology, virology and parasitology Department, University of Medicine, Pharmacy, Science and Technology of Târgu Mures, Romania \\ 5. Pathology Department, Colentina University Clinical Hospital, Bucharest, Romania \\ 6. Pathophysiology Department, University of Medicine, Pharmacy, Science and Technology of Târgu Mures, Romania
}

Objective: The study aims to analyze obesogenic behavioral patterns of adolescents living in Mureș County, Romania, as well as to establish a relationship between these behaviors and their Body Mass Index (BMI), in an attempt to provide effective prevention strategies for obesity. Material and Methods: 153 students between 9th to 12th grade, aged between 14 and 19 years old, from the Vocational and Art Highschool of Târgu Mureș were included in the study. All the candidates filled out an evaluation questionnaire of lifestyle and risky behaviors. The analyzed data were sex, age, residence, BMl and risky eating behavior defined as the consumption of carbohydrates (bread, potatoes, sweets), sodas, junk food, alcohol (wine, distilled beverages, beer), beer separately, level of physical activity (school and extra-school sports activities), sedentary behaviors ( $\geq 2$ hours/day in front of a screen: personal computer-PC and television-TV), and spending $\geq 2$ hours/day separately on the PC and on the TV. Results: A statistically significant association was observed between BMl and consumption of fast-food, tobacco, beer, sedentary behavior and spending $\geq 2$ hours/day in front of the PC. Moreover, there was a statistically significant difference between the BMI values of adolescents presenting all studied risk behaviors compared to those who did not. Conclusions: Obesity among adolescents from Mureș County is influenced by lifestyle choices like fast-food, tobacco, beer, sedentary behavior and spending $\geq 2$ hours/ day in front of the PC.

Keywords: BMI, adolescents, risk behavior

Received 08 July 2019 / Accepted 02 September 2019

\section{Introduction}

The global prevalence of obesity almost tripled from 1975 to 2016 [1], as obesity has become a global epidemic even for the young ones: children and teenagers (from $4 \%$ in 1976 to $18 \%$ in 2016) [2,3]. According to World Health Organization (WHO), in 2016 over 340 million children and teenagers ( 5 to 19 years) were overweight or obese [1]. Although initially obesity was considered a disease that affected developed countries, after the transformations that occured between 1980-1990, a sudden increase was also manifested in Eastern European countries [4].

Obesity occurs as a nutritional imbalance when energy intake exceeds caloric expenditure. The multifactorial etiology of this disease is dependent on a series of behavioral patterns that are prone to predispose an individual to become obese. Notable examples of obesogenic behaviors include:

Alcohol consumption: according to the WHO [5], 15 years old adolescent drinks 6.3 liters of pure alcohol/year or 13.5 grams of pure alcohol/day.

Fast food intake: the fast-paced lifestyle that characterizes the current society impacts every aspect of human life, including dietary habits. Fast food diet, rich in fat, salt and meat products has slowly replaced the traditional cuisine.

* Correspondence to: Dana-Valentina Ghiga

E-mail: dana.ghiga@umfst.ro
Adolescents are often eating fast food, although these aliments fail in providing the daily necessities of vitamins and minerals.

Sweets and Sugar-Sweetened Beverage Consumption $(S S B C)$ : children and teenagers with high consumption of sweets and SSBC have an increased risk for developing metabolic syndrome, abdominal obesity, and arterial hypertension [6]. Moreover, SSBC intake has been associated with high triglyceride level, a high waist circumference, as well as high blood pressure [7]. Subsequently, WHO states that a diet high in sugary products has no proven benefits and, as a consequence, reduced free sugars intake is recommended [8].

Smoking: the WHO European region leads in the number of both adult and teenager's smokers ( $28 \%$ and $12 \%$ ). Although the global sex distribution of smokers showed that $12 \%$ of them are male and $11 \%$ are female, in Romania $37.4 \%$ of the male population smokes, as well as $16.7 \%$ of the female population [9]. Smoking is responsible for 7.2 million deaths/year, killing more individuals than acquired immunodeficiency syndrome, malaria, and tuberculosis combined [10].

Physical activity: data from Romania showed that in 2018 only $23 \%$ of children and teenagers aged $\leq 13$ years old had a satisfactory level of physical activity, $29 \%$ of each were boys and $17 \%$ of each were girls. On the other hand, 
$30 \%$ of teenagers and adults aged $\geq 15$ years old reported a proper level of physical activity [11].

Sedentariness (activities like watching TV and spending time in front of a computer): The American Pediatrics Association recommends less than 2 hours/day of entertainment screen time for children and adolescents [12]. Children are exposed to 25000 TV advertisements/ year, approximately $20 \%$ of each promoting food and drinks products [13].

A high BMI in childhood and adolescence is associated with a high obesity risk during adulthood, as well as with an increased risk of premature death [14,15]. Also, it has been proven that obesity during childhood and adolescence impacts adult life in various ways, by increasing the cardiometabolic risk (the patients are more prone to develop Diabetes Mellitus, Hypertension, ischemic heart disease or even Stroke) and also by favoring the onset of pathologies like bronchial asthma or polycystic ovary syndrome [16].

Moreover, obesity during youth is associated with various musculoskeletal disorders, psychological conditions and different malignancies (endometrial, breast, ovarian, prostate, liver, biliary bladder, kidney and colon cancer) [1].

The development of a project to evaluate the dimension of risk behaviors in adolescents represents the opening of a sphere of major problems, both in society and in the medical world, namely efficient prevention. Good management is represented by the knowledge of the dimensions of the phenomenon and of the bio-psycho-social particularities, which is why we consider that updating risk behaviors in adolescents is very important. Preventing obesity should remain a priority because the continuous transformation of living conditions predisposes to new risk factors, that the study aims to evaluate the local obesogenic behavioral pattern and to evaluated the relationship between BMI and risk behaviors in adolescents living in Mureş County. Our findings will expand the database and will support future obesity prevention programs knowing the current state of adolescent behavior.

\section{Material and Methods}

A cross-sectional study was performed in Mures County, in June 2019, to evaluate the relationship between BMI and the behavioral patterns of adolescents that can lead to obesity. The study was approved by the Ethics Committee of the College of Physicians in Romania and it follows the Helsinki Declaration principles.

153 students from the High School of the Arts, Târgu Mureș, aged between 14 and 19, were asked to anonymously answer a 20 questions questionnaire to identify obesogenic risk behaviors. Each questionnaire was completed in 50 minutes, under similar conditions. Informed consent was presented and granted. The school principal and all participants in the study agreed to the processing and presentation of the data.

\section{Tracked parameters:}

- Demographics: gender, age, background

- BMI (kg/m2)

- Dietary habits: Sweets and SSBC consumption, fastfood, bread and potatoes intake

- Alcohol (wine, distilled beverages or beer) and tabacco consumption

- Physical activity level: school and extra-school sports activities

- Sedentary behaviors: $\geq 2$ hours/day time spent in the front of a screen (television and personal computer), and separately, just in front of a television (TV) and just in front of a personal computer (PC).

The data analysis included descriptive statistics elements (frequency, percentage, confidence interval 95\%, mean, median, standard deviation) and inferential statistics. The D'Agostino \& Pearson test was applied to determine data normal distribution. For comparison of medians, the Mann-Whitney test, non-parametric test, and Spearman test for correlation determination were applied. The level of significance was set for 0.05 . The statistical analysis was performed using the GraphPad Prism 7 utility, the Trial version.

\section{Results}

The analyzed group included $11.11 \%$ (17, with BMI $\leq 18.4)$ underweight students, $79.08 \%(121, \mathrm{BMI}=18.5-24.9)$ students with normal BMI, 8.5\% (13, BMI >25.0-29.9) overweight and $1.31 \%(2, \mathrm{BMI} \geq 30)$ obese students. The description of the study group in terms of risk behaviors is presented in Table I.

Table II represent the mean \pm SD (median) of BMI in adolescents with risk behavior and without it, and $\mathrm{p}$ shows if there whether or not a statistically significant difference between the median values of BMI in those with and without consumption.

We found statistical significant positive correlations $(\mathrm{p}<0.05)$ between the BMI and the excessive hours spent in front of the PC $(r=0.3494$, CI 95\%: 0.1973-0.4850), as well as total time spend in front of the PC and the TV ( $\mathrm{r}$ $=0.3023$, CI 95\%: 0.1462-0.4437).

\section{Discussions}

The results of the current study show that most of the young people in the targeted group have a normal weight, but also a large proportion of the students express obesogenic behaviors. There is a proven correlation between the studied behavioral patterns and the value of BMI.

According to Donna Spruijt-Metz, three major behaviors are influencing obesity: food intake, physical activity and sleep [17]. The findings of the study are consistent with other studies on obesity among young people from a cultural and socioeconomic background that resembles countries like Romania, countries where a rapid transition in dietary habits have been observed, mainly due to 
Table I. The description of the studied group in terms of risk behaviors

\begin{tabular}{|c|c|c|c|c|}
\hline \multicolumn{2}{|l|}{ Parameter studied } & \multirow{2}{*}{$\begin{array}{c}\text { Frequency } \\
97\end{array}$} & \multirow{2}{*}{$\begin{array}{c}\text { Percentage } \\
63.40 \%\end{array}$} & \multirow{2}{*}{$\begin{array}{c}\text { Confidence interval (95\%) } \\
55.24 \%-71.03 \%\end{array}$} \\
\hline Gender & Female & & & \\
\hline & Male & 56 & $36.60 \%$ & $28.97 \%-44.76 \%$ \\
\hline \multirow[t]{2}{*}{ Living area } & Rural & 36 & $23.53 \%$ & $17.06 \%-31.06 \%$ \\
\hline & Urban & 117 & $76.47 \%$ & $68.94 \%-82.94 \%$ \\
\hline \multicolumn{2}{|c|}{ Daily sweet beverages consumption } & 74 & $48.37 \%$ & $40.22 \%-56.58 \%$ \\
\hline \multirow[t]{2}{*}{ Sweets intake } & Moderate (2-3 days/week) & 17 & $11.11 \%$ & $6.61 \%-17.19 \%$ \\
\hline & High (daily) & 90 & $58.82 \%$ & $50.59 \%-66.71 \%$ \\
\hline \multicolumn{2}{|c|}{ Daily bread and potatoes consumption } & 127 & $83.01 \%$ & $76.10 \%-88.59 \%$ \\
\hline \multirow[t]{2}{*}{ Fast-food consumption } & Moderate (1 days/week - 2 days/month) & 66 & $43.14 \%$ & $35.17 \%-51.38 \%$ \\
\hline & $\operatorname{High}(\geq 2-3$ day/week) & 34 & $22.22 \%$ & $15.91 \%-29.64 \%$ \\
\hline \multirow[t]{2}{*}{ Physical activity level } & Moderate ( $\geq 1$ day/week school or extra-school sports activities) & 32 & $20.92 \%$ & $14.77 \%-28.22 \%$ \\
\hline & Sustained ( $\geq 1$ day/week school and $\geq 1$ day/week extra-school sports activities) & 115 & $75.16 \%$ & $67.54 \%-81.79 \%$ \\
\hline \multirow[t]{2}{*}{ Smoking habits } & Moderate (2-10 cigarettes/day) & 60 & $39.22 \%$ & $31.43 \%-47.43 \%$ \\
\hline & Sustained (>10 cigarettes/day) & 8 & $5.23 \%$ & $2.28 \%-10.04 \%$ \\
\hline \multicolumn{2}{|c|}{ Alcohol intake ( $\geq 1$ day/week of wine, distilled beverages or beer) } & 115 & $75.16 \%$ & $67.54 \%-81.79 \%$ \\
\hline \multicolumn{2}{|c|}{ Only beer consumption ( $\geq 1$ day/week) } & 64 & $41.83 \%$ & $33.92 \%-50.07 \%$ \\
\hline \multicolumn{2}{|c|}{ Sedentariness ( $\geq 2$ hours/day total time spent in the front of a screen) } & 119 & $77.78 \%$ & $70.36-84.09 \%$ \\
\hline \multicolumn{2}{|c|}{$\mathrm{PC} \geq 2$ hours/day } & 98 & $64.05 \%$ & $55.91 \%-71.64 \%$ \\
\hline \multicolumn{2}{|l|}{ TV $\geq 2$ hours/day } & 43 & $28.10 \%$ & $21.14 \%-35.93 \%$ \\
\hline
\end{tabular}

Table II. Influence of risk behavior vs risk-free behavior on BMI

\begin{tabular}{|c|c|c|c|}
\hline Parameter studied & Yes - mean \pm SD (median) & No - mean $\pm S D$ (median) & $\mathbf{p}$ \\
\hline Sweets intake & $21.43 \pm 2.72(21.20)$ & $21.70 \pm 2.99(21.35)$ & 0.4652 \\
\hline Bread and potatoes consumption & $21.54 \pm 2.79(21.20)$ & $21.38 \pm 2.86(21.35)$ & 0.8383 \\
\hline Daily sweet beverages consumption & $21.92 \pm 2.74(21.40)$ & $21.13 \pm 2.81(21.00)$ & 0.0855 \\
\hline Fast-food consumption & $21.81 \pm 2.62(21.35)$ & $20.95 \pm 3.05(20.10)$ & 0.0382 \\
\hline Physical activity & $21.54 \pm 2.79(21.35)$ & $20.88 \pm 3.01(20.55)$ & 0.5888 \\
\hline Smoker & $22.05 \pm 2.84(21.60)$ & $21.08 \pm 2.70(20.90)$ & 0.0289 \\
\hline Alcohol intake & $21.65 \pm 2.95(21.40)$ & $21.08 \pm 2.26(20.95)$ & 0.3048 \\
\hline Beer consumption & $22.51 \pm 3.03(21.95)$ & $20.79 \pm 2.38(20.83)$ & 0.0004 \\
\hline Sedentariness & $21.73 \pm 2.66(21.30)$ & $20.74 \pm 3.14(20.15)$ & 0.0367 \\
\hline$P C \geq 2$ hours/day & $22.06 \pm 2.62(21.45)$ & $20.53 \pm 2.86(20.20)$ & 0.0008 \\
\hline$T V \geq 2$ hours/day & $21.51 \pm 3.02(21.00)$ & $21.51 \pm 2.71(21.30)$ & 0.8407 \\
\hline Risk behavior & $22.53 \pm 3.20(22.10)$ & $21.25 \pm 2.63(21.10)$ & 0.0338 \\
\hline
\end{tabular}

urbanization. For example, although most of the Iranian cuisine is made up of bread and rice, bread consumption among Iranian adolescents is $58.4 \%$, lower than that in our study [18].

Another study among adolescents living in Târgu Mureş indicates that $55.30 \%$ of teenagers are consuming sweetened drinks [19], a percentage close to the group in our study $(48.37 \%)$.

In the United States, on the other hand, the trend towards tobacco consumption among adolescents is declining. A study performed for 18 years over students living in Arkansas, USA, shows a decrease in tobacco consumption from $74.4 \%$ in 1995 to $52.1 \%$ in 2013 [20], possibly due to successfully conducted prevention programs. Moreover, there is a proven association between alcohol intake and tobacco consumption, people who consume alcohol are more likely to smoke [21]. In their study, Akbartabartoori et al found that cigarette smoking negatively affects BMI just in adults over 24 years especially in men, but not in younger people. In women, smoking is associated to central adiposity, in contrast to men witch is not, but a reduction in muscle mass could suggest a lower hip circumference [22]. Interesting, Chiolero et al found that nicotine has two effects: increasing energy expenditure and reducing appetite in the short term, and in contrast, in long term, heavy smokers associate a higher BMI than light smokers or nonsmokers, because of an accumulation of many risky behaviors besides smoking like low physical activity and poor diet that lead to weight gain. Also, smoking is associated with increases insulin resistance and central fat accumulation [23].

In the 2015 ESPAD project, it is reported that almost all Europeans aged 15-16 years old consumed alcohol at least once in their lives (35-96\%). The highest consumption rates occur in the Czech Republic, Albania, and Hungary, while the smallest ones are in Iceland, Macedonia, and Norway [24].

According to the results of the current study, there is no statistically significant difference between adolescents who consume alcohol and BMI value, but when the beer consumption was analyzed separately, a relationship between beer consumption and BMI was noticed. Beer has a higher level of carbohydrate as compared to other alcoholic beverages.

There are studies that demonstrate that excessive time spent on the Internet has negative effects on adolescents such as affecting communication and face-to-face interaction with family and friends [25], physical activity [26], 
proper eating habits [27], sleeping [28], completing academic tasks [29], also the time spent online is directly proportional to the Internet dependency [30]. According to Griffiths, there are six symptoms presents in pathological Internet users (PIU): salience (more online activities), mood modification (using the Internet as a method of reducing stress), tolerance (need to be more online), withdrawal (increasing the level of depression and irritability in the offline world), conflicts and relapse (failed to disconnect) [31].

Tony Durkee et al classified Internet users into three groups of Internet users: adaptive, maladaptive, and PIU. Results showed a higher prevalence among pathological users compared to the others at risk-behaviors such as poor sleeping habits, tobacco use, physical inactivity and also multiple risk-behaviors was associated with the PIU group (89.9\%) [32].

According to a study conducted in Brazil on 6529 teenagers, there is an association between various behaviors like spending time in front of a PC, low levels of physical activity and consumptions of fruits/vegetables and high alcohol intake. Boys living in urban areas are more predisposed to expressing obesogenic behaviors. $21.2 \%$ of the total number of participants presented at least one risky behavior, while $37.3 \%$ presented two, $28.5 \%$ had three, and $8.0 \%$ had all the risky behavior mentioned above [33].

Also, the current study states a linkage between BMI and time spend on in front of the PC ( $\geq 2$ hours/day), although there is no direct correlation between BMI and the time spent in front of the TV, probably because entertainment preferences of teenagers have changed over the past years. These results are partially following Roya Kelishadi's study on Iranian teens, where BMI was linked directly to time spent in front of PC/TV $(\geq 2)[20]$.

The study presents a series of limitations. Firstly, there is a relatively small number of participants in the study, all of them being students in the same high school, therefore the data could not be extrapolated and be representative for a region. Because the material and methods of the study were based on a questionnaire, there was also noted a bias of subjectivity and accuracy from the participants.

Another limitation consists in the design of the study. Taking into consideration that the design is cross-sectional, it only offers one snapshot of the current risky behaviors among teenagers, and therefore it cannot predict, follow up and evaluate the consequences in the long term. In the future, the study will extend to a larger population and the study design will be converted so that the data could be representative.

Constant re-evaluation of data regarding the teenager's lifestyle is a useful tool in a modern society where health and quality of life are fundamental for a long prosper life. The emergence of new risk factors for obesity, as well as the continuous transformation of living conditions among people everywhere, explains the need for adequate prevention campaigns against obesity. It is necesary to elaborate more efficient community intervention in schools, to insure the informations about the risks of obesity and ways to reduce it.

\section{Conclusions}

There is an association between BMI and the teenagers' predisposition for fast food, cigarettes, beer consumption, sedentary behavior and spending $\geq 2$ hours/day in front of a PC. There is a statistically significant difference between the BMI of adolescents presenting all risk behaviors studied compared with those who do not have them.

\section{Authors'contribution}

Irina-Bianca Kosovski, M.D. (Conceptualization; Data curation; Investigation; Resources; Writing - original draft) Dana-Valentina Ghiga, Lecturer, PhD, M.D. (Methodology; Supervision; Validation; Writing - review \& editing) Monica Tarcea, Professor, PhD, M.D. (Supervision; Validation; Writing - review \& editing)

Cristina Nicoleta Ciurea, Assistant Professor, M.D. (Data curation; Writing - review \& editing)

Ana Ioana Savin, M.D. (Data curation; Writing - review \& editing)

Anca Bacârea, Associate Professor, PhD, M.D. (Conceptualization; Project administration; Supervision; Validation; Visualization; Writing - review \& editing)

\section{Conflict of interest}

None to declare.

\section{References}

1. Obesity and overweight. https://www.who.int/news-room/fact-sheets/ detail/obesity-and-overweight, June 12th 2019.

2. Wang Y, Lobstein TIM. Worldwide trends in childhood overweight and obesity. Int J Pediatr Obes. 2006;1:11-25.

3. Janssen I, Katzmarzyk PT, Boyce WF, et al. Comparison of overweight and obesity prevalence in school-aged youth from 34 countries and their relationships with physical activity and dietary patterns. Obes Rev. 2005;6:123-132.

4. Ulijaszek SJ, Koziel S. Nutrition transition and dietary energy availability in Eastern Europe after the collapse of communism. Econ Hum Biol. 2007;5:359-369.

5. World Health Statistics 2016: Monitoring health for the SDGs. http:// www.who.int/gho/publications/world_health_statistics/2016/en/, June 12 th 2019.

6. Mirmiran P, Yuzbashian E, Asghari G, et al. Consumption of sugarsweetened beverage is associated with the incidence of metabolic syndrome in Tehranian children and adolescents. Nutr Metab (Lond). 2015;2:25.

7. Ejtahed HS, Bahadoran Z, Mirmiran P, et al. Sugar-sweetened beverage consumption is associated with metabolic syndrome in Iranian adults: Tehran lipid and glucose study. Endocrinol Metab (Seoul), 2015;30:334342.

8. WHO - Guideline: sugars intake for adults and children, Geneva, 2015, available at http://apps.who.int/iris/bitstream/handle/10665/149782/ 9789241549028 _eng.pdf?sequence=1, June 12th 2019.

9. Health impact of tobacco control policies in line with the $\mathrm{WHO}$ Framework Convention on Tobacco Control (WHO FCTC). http://www. euro.who.int/__data/assets/pdf_file/0007/312595/Tobacco-controlfact-sheet-Romania.pdf, June 23th 2019.

10. Tobacco, Data and statistics. http://www.euro.who.int/en/health-topics/ disease-prevention/tobacco/data-and-statistics, June 29th 2019.

11. Romania physical activity factsheet 2018. http://www.euro.who.int/ data/assets/pdf_file/0005/382577/romania-eng.pdf, June 29th 2019. 
12. Strasburger VC, Hogan MJ, Mulligan DA, et al. Children, adolescents, and the media. Pediatrics. 2013;132:958-961.

13. Santaliestra-Pasías AM, Rey-López JP, Aznar LAM - Obesity and sedentarism in children and adolescents: what should be bone?. Nutr Hosp. 2013;28:99-104.

14. Guo SS, Wu W, Chumlea WC, et al. Predicting overweight and obesity in adulthood from body mass index values in childhood and adolescence. The American journal of clinical nutrition. 2002;76:653-658.

15. Engeland A, Bjørge T, Tverdal A, et al. Obesity in adolescence and adulthood and the risk of adult mortality. Epidemiology. 2004;15:79-85.

16. Reilly JJ, KellyJ. The long-term impact of overweight and obesity in childhood and adolescence on morbidity and premature mortality in adulthood: a systematic review. International journal of obesity. 2011;35:891-898.

17. Spruijt-Metz D. Etiology, treatment, and prevention of obesity in childhood and adolescence: A decade in review. J Res Adolesc. 2011;21:129-152

18. Kelishadi R, Ardalan G, Gheiratmand R, et al. Association of physical activity and dietary behaviors with the body mass index in a nationa sample of Iranian children and adolescents: CASPIAN Study. Bull World Health Organ. 2007;85:19-26

19. Salcudean M, Rus V, Ruta F, et al. Eating Behaviour and Food Preferences of Tîrgu Mures High School Students. Acta Medica Marisiensis. 2018;64:157-160.

20. Mattingly TN, Thapa PB, Messias E. Trends in Lifetime use of Tobacco, Alcohol, and Cannabis among Arkansas Teens from 1995 to 2013. J Ark Med Soc. 2016;113:90-93.

21. Vlaicu B, Petrescu C, Fira-Mlădinescu C, Fira-Mlădinescu O, Ursoniu S, Putnoky S, Vernic C, Suciu O, Vlaicu Ș, Silberberg K, Korbuly B, Ciobanu V, Caraion C, Radu I, Mancas S, Moldovan R, Petrescu P, Bagiu R, Romoșan F, Dehelean P, Dehelean L. Comportamente cu risc la studenții din județul Timiș. Timișoara. Ed. EUROBIT, 2009, 200-207.

22. Akbartabartoori M, Lean MEJ, Hankey CR. Relationships between cigarette smoking, body size and body shape. Int J Obes (Lond). 2005;29:236
23. Chiolero A, Faeh D, Paccaud F, et al. Consequences of smoking for body weight, body fat distribution, and insulin resistance. Am J Clin Nutr. 2008;87:801-809.

24. ESPAD Report 2015, Results from the European School Survey Project on Alcohol and Other Drugs. http://www.espad.org/sites/espad.org/ files/TD0116475ENN.pdf, June 29th 2019.

25. Nie NH, Hillygus DS, Erbring L. Internet use, interpersonal relations, and sociability: A time diary study, in Wellman B, Haythornthwaite C (eds): The Internet in Everyday Life. Blackwell Publishers Ltd, Oxford, 2002, 213-243.

26. Peltzer K, Pengpid S, Apidechkul T. Heavy internet use and its associations with health risk and health-promoting behaviors among Thai university students. Int. J. Adolesc. Med. Health. 2014;26:187194.

27. Gür K, Yurt S, Bulduk S, et al. Internet addiction and physical and psychosocial behavior problems among rural secondary school students. Nurs. Health Sci. 2015;17:331-338.

28. Punamaki RL, Wallenius $\mathrm{M}, \mathrm{Nygard} \mathrm{CH}$, et al. Use of information and communication technology (ICT) and perceived health in adolescence: The role of sleeping habits and waking-time tiredness. J. Adolesc. 2007;30:569-585

29. Akhter N. Relationship between internet addiction and academic performance among university undergraduates. Edu. Res. Rev. 2013;8:1793.

30. Straker L, Pollock C, Maslen B. Principles for the wise use of computers by children. Ergonomics. 2009;52:1386-1401.

31. Pontes HM, Kiraly O, Demetrovics Z, et al. The conceptualization and measurement of DSM-5 Internet Gaming Disorder: The development of the IGD-20 Test. PloS one. 2014;9:e110137.

32. Durkee, T, Carli V, Floderus B, et al. Pathological internet use and risk-behaviors among European adolescents. Int J Environ Res Public Health. 2016;13:294.

33. Silva KS, Barbosa Filho VC, Del Duca GF, et al. Gender differences in the clustering patterns of risk behaviors associated with non-communicable diseases in Brazilian adolescents. Prev Med. 2014;65:77-81. 